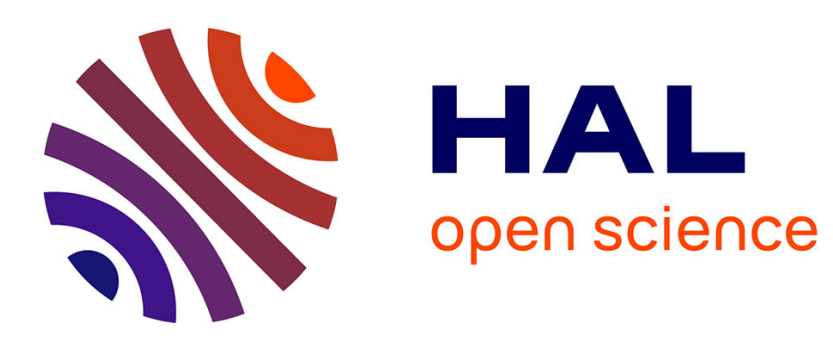

\title{
Internal Friction Study on Manet Steel : Effects of Cooling Rate from Austenitic Domain
}

\author{
P. Gondi, R. Montanari, M. Tata
}

\section{To cite this version:}

P. Gondi, R. Montanari, M. Tata. Internal Friction Study on Manet Steel: Effects of Cooling Rate from Austenitic Domain. Journal de Physique IV Proceedings, 1996, 06 (C8), pp.C8-115-C8-118. 10.1051/jp4:1996822 . jpa-00254630

\section{HAL Id: jpa-00254630 https://hal.science/jpa-00254630}

Submitted on 1 Jan 1996

HAL is a multi-disciplinary open access archive for the deposit and dissemination of scientific research documents, whether they are published or not. The documents may come from teaching and research institutions in France or abroad, or from public or private research centers.
L'archive ouverte pluridisciplinaire HAL, est destinée au dépôt et à la diffusion de documents scientifiques de niveau recherche, publiés ou non, émanant des établissements d'enseignement et de recherche français ou étrangers, des laboratoires publics ou privés. 


\title{
Internal Friction Study on Manet Steel: Effects of Cooling Rate from Austenitic Domain
}

\author{
P. Gondi, R. Montanari and M.E. Tata \\ Dip. Ingegneria Meccanica, Università di Roma "Tor Vergata", Via della Ricerca Scientifica s.n.c., \\ 00133 Roma, Italy
}

\begin{abstract}
Snoek type $\mathrm{Q}^{-1}$ peaks observed in $\mathrm{Fe}-\mathrm{Cr}-\mathrm{C}$ alloys are related to jumps between equivalent octahedra or tetrahedra with $\mathrm{n} \mathrm{Cr}$ atoms at the corners, with $\mathrm{n}$ up to 6 or 4 . The effects of high $\mathrm{T}$ and cooling treatments are considered on the characteristics of the $\mathrm{C}-\mathrm{Cr}_{\mathbf{n}}$ associates and in consequence of martensite. The results are interpreted in terms of $\mathrm{C}-\mathrm{Cr}_{\mathbf{n}}$ associates acting as embryos for the nucleation of martensite with stability depending on tetrahedrality or octahedrality of the associates .
\end{abstract}

\section{INTRODUCTION}

The basic references are two papers, of Tomilin et al. [1] and of Gondi et al. [2]. In Fe-Cr-C alloys Tomilin et al. observed the occurrence of seven $Q^{-1}$ vs. T peaks considered of Snoek type, that is due to interstitial C jumping between neighbouring octahedra with $\mathrm{Cr}$ atoms, in number $\mathrm{n}$ from 0 to 6 , substituting $\mathrm{Fe}$ at the corners in the body centered structure. The height of the observed peaks was interpreted $[1,3]$ in terms of Poisson distribution of single $\mathrm{C}-\mathrm{Cr}_{\mathrm{n}}$ associates with account for the energies of binding of $\mathrm{C}$ to the $\mathrm{Cr}$ atoms. In the Cr martensitic steel MANET Gondi et al. observed that the height of these peaks depends on thermal treatments and their results were interpreted by assuming that reversible jumps between equivalent sites, i.e. $\mathrm{C}-\mathrm{Cr}_{\mathrm{n}}$ cells with the same $\mathrm{n}$ and with common face, have to be considered as contributing to each peak.

Following results presented previously [4], the effects of austenitising temperature and cooling rate on martensite characteristics are considered in this paper in connection with the martensite properties due to the presence of the $\mathrm{Cr}$ atoms in solution.

\section{EXPERIMENTAL}

The material used is a MANET1 steel with the following composition in wt\%: C 0.17, Cr 10.5, Ni 0.85, Mn 0.60, Mo 0.50, Nb 0.20, V 0.25, Si 0.32, Al 0.05, N 0.003, P 0.005. After cold rolling to $0.5 \mathrm{~mm}$ thickness and cutting, the samples were austenitised at $T_{a}=1348 \mathrm{~K}$; batch $A$ of samples was cooled from $T_{a}$ with a rate of $150 \mathrm{~K} / \mathrm{min}$, batch $B$ quenched with a rate of $3600 \mathrm{~K} / \mathrm{min}$, batch $C$ with a two stage cooling, first with $150 \mathrm{~K} / \mathrm{min}$ down to 1073 then with $3600 \mathrm{~K} / \mathrm{min}$ to RT.

Internal friction $Q^{-1}$ measurements were done using frequency modulation with amplitudes $<10^{-6}$, with frequencies $\sim 250 \mathrm{~Hz}$ and temperatures increasing from $\mathrm{RT}$ to $773 \mathrm{~K}$ with a rate of $2 \mathrm{~K} / \mathrm{min}$. Together with $\mathrm{Q}^{-}$ ${ }^{1}$ the dynamic modulus was also measured; the dynamic modulus variations were consistent with $\mathrm{Q}^{-1}$ peaks depending on anelasticity.

\section{RESULTS}

Fig.1-a shows the $Q^{-1}$ vs $T$ data as measured with the samples of batch $A$ with cooling rate of $150 \mathrm{~K} / \mathrm{min}$, in fig.1-c the trend due to subsequent heating for $1 \mathrm{hr}$ at $373 \mathrm{~K}$. In fig.1-b the $\mathrm{Q}^{-1}$ vs $T$ data after fast cooling $(3600 \mathrm{~K} / \mathrm{min}$-batch B) with effects of subsequent heating for $1 \mathrm{hr}$ at $373 \mathrm{~K}$ in fig.1-d are presented. 
As mentioned in the introduction these peaks have been related to jumps between octahedra with $\mathrm{n}$ corners occupied by $\mathrm{Cr}$ atoms, with $\mathrm{n}$ up to 6 . The $\mathrm{Q}^{-1}$ spectrum is thus considered as corresponding to

$$
Q^{-1}=\sum_{n=0}^{n=6} \frac{\Delta_{n} \omega \tau_{0} \exp \left(H_{n} / k T\right)}{1+\left[\omega \tau_{o} \exp \left(H_{n} / k T\right)\right]^{2}}
$$

$\mathrm{H}_{n}=\mathrm{H}_{0}+\mathrm{n} \Delta \mathrm{H}, \Delta \mathrm{H}=13 \mathrm{~kJ} / \mathrm{mole}$ binding energy of $\mathrm{C}$ to $\mathrm{Cr}[1,2], \mathrm{H}_{0}=83.7 \mathrm{~kJ} / \mathrm{mol}$ and $\tau_{0}=5.010^{-15} \mathrm{~s}$ respectively activation energy and pre-exponential factor of the Snoek peak, $\Delta_{n} / 2$ the height of peaks connected to $\mathrm{C}-\mathrm{Cr}_{\mathbf{n}}$ associates.

The markers at the top of the figures correspond to the position of the different peaks for the $n$ values in labels, of course on account of the corresponding binding energy, as used in the bibliography.

After slow cooling the measurements show two $Q^{-1}$ peaks corresponding to $C-C_{6}$ and $C-C r_{4}$ and after fast cooling two peaks corresponding to $\mathrm{C}-\mathrm{Cr}_{4}$ and $\mathrm{C}-\mathrm{Cr}_{2}$ associates.

As shown in fig. 1-c, the situation after slow cooling appears unstable and transforms after heating at $373 \mathrm{~K}$ in conditions giving rise to a strong peak corresponding to $\mathrm{C}_{-} \mathrm{Cr}_{4}$ associates plus a broad peak in the region

$\mathrm{C}-\mathrm{Cr}_{0} \Leftrightarrow \mathrm{C}-\mathrm{Cr}_{1}$.

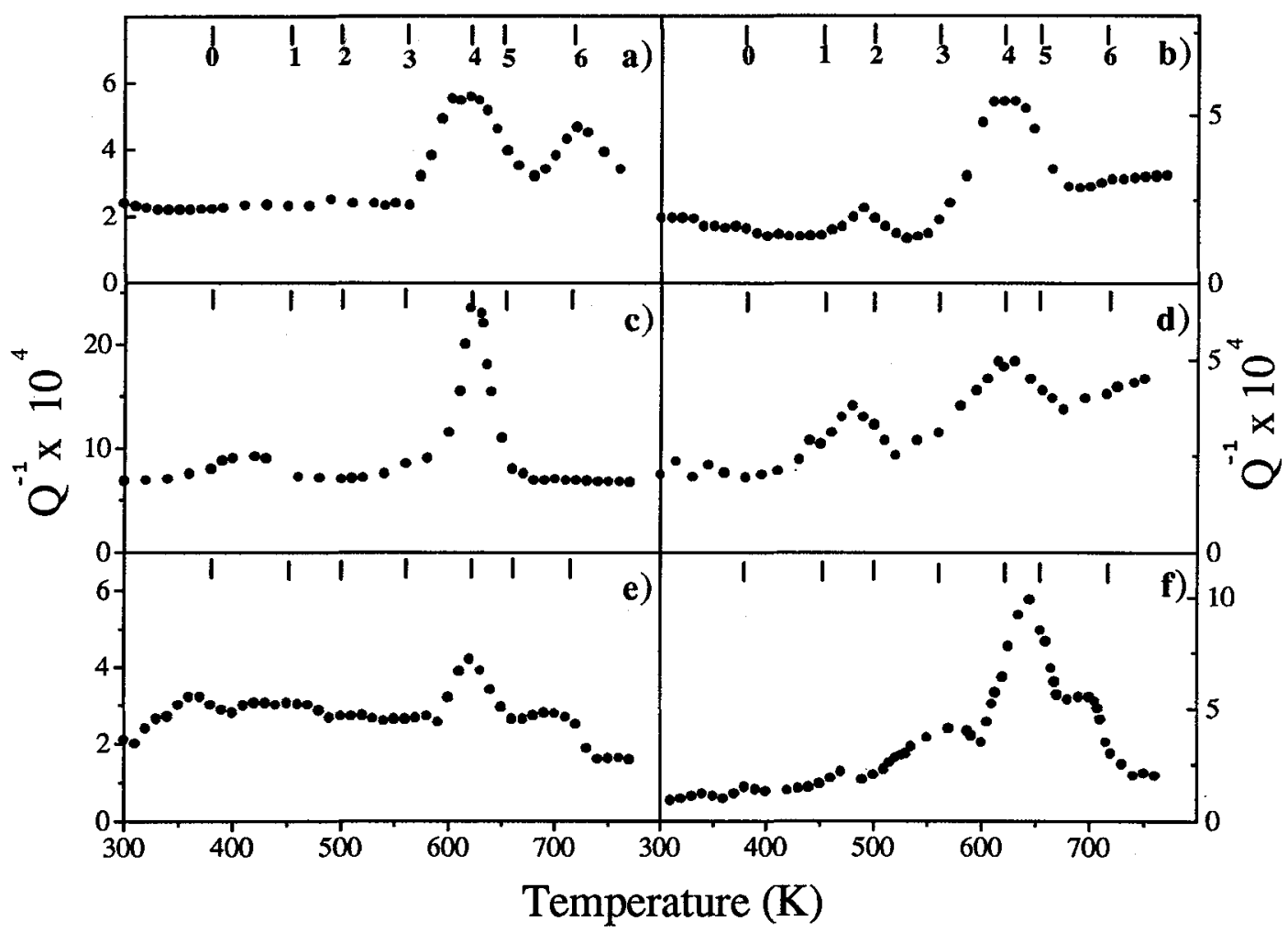

Figure 1: $Q^{-1}$ vs. T trends of MANET samples first austenitised at $1348 \mathrm{~K}$ and then cooled with rates of $150 \mathrm{~K} / \mathrm{min}$ down to room T (1-a), $3600 \mathrm{~K} / \mathrm{min}$ down to RT (1-b), first $150 \mathrm{~K} / \mathrm{min}$ down to $1073 \mathrm{~K}$ and in sequence $3600 \mathrm{~K} / \mathrm{min}$ to RT (1-e). In fig.s 1-c-d-f effects of subsequent heating at $373 \mathrm{~K}$ respectively for the samples of fig.s 1-a-b-e. Numbers $\mathrm{n}$ at the top of fig.s represent positions of peaks related to octahedra with $\mathrm{n} \mathrm{Cr}$ atoms at the corners.

Greater structural stability does instead occur after fast cooling since the $Q^{-1}$ spectra remains approximately unchanged by heating up to relatively high temperatures (fig.1-d). 
As reported in other papers this greater stability is confirmed by observations of the $\mathrm{X}$-ray diffraction line breadths [2,4], small angle neutron scattering [5] and fracture behaviour after the various thermal treatments [6].

To ascertain the range of temperatures where the characteristics connected with slow cooling occur, the tests have been made with slow cooling down only to $1073 \mathrm{~K}$ followed by fast cooling (batch $\mathrm{C}$ ). The temperature of $1073 \mathrm{~K}$ is situated in the range of the transition from the $\gamma$ to the $\alpha$ phase. Fig.1-e shows the $\mathrm{Q}^{-1}(\mathrm{~T})$ trend after this treatment and fig.1-f illustrates the effects of subsequent heating at $373 \mathrm{~K}$; the results are typical of the behaviour obtained with constant slow cooling from the austenitisation temperature, thus indicating that the martensite structure after slow cooling depends on the structural characteristics coming about at the onset of the $\gamma$ to $\alpha$ transformation.

\section{DISCUSSION}

With reference to the treatments $\mathrm{A}$ and $\mathrm{C}$ of continuous slow cooling or initial slow cooling to $1073 \mathrm{~K}$ followed by quenching it is noticed that even if the $\gamma$ to $\alpha$ transformation occurs slowly at the temperatures near the phase transformation boundary, the formation of nuclei of bec cells may be assumed for this slow cooling treatments consistently with couples of octahedral interstices with a common face and with all corners occupied by $\mathrm{Cr}$, as required for the occurrence of the $\mathrm{C}_{-} \mathrm{Cr}_{6}$ peak observed.
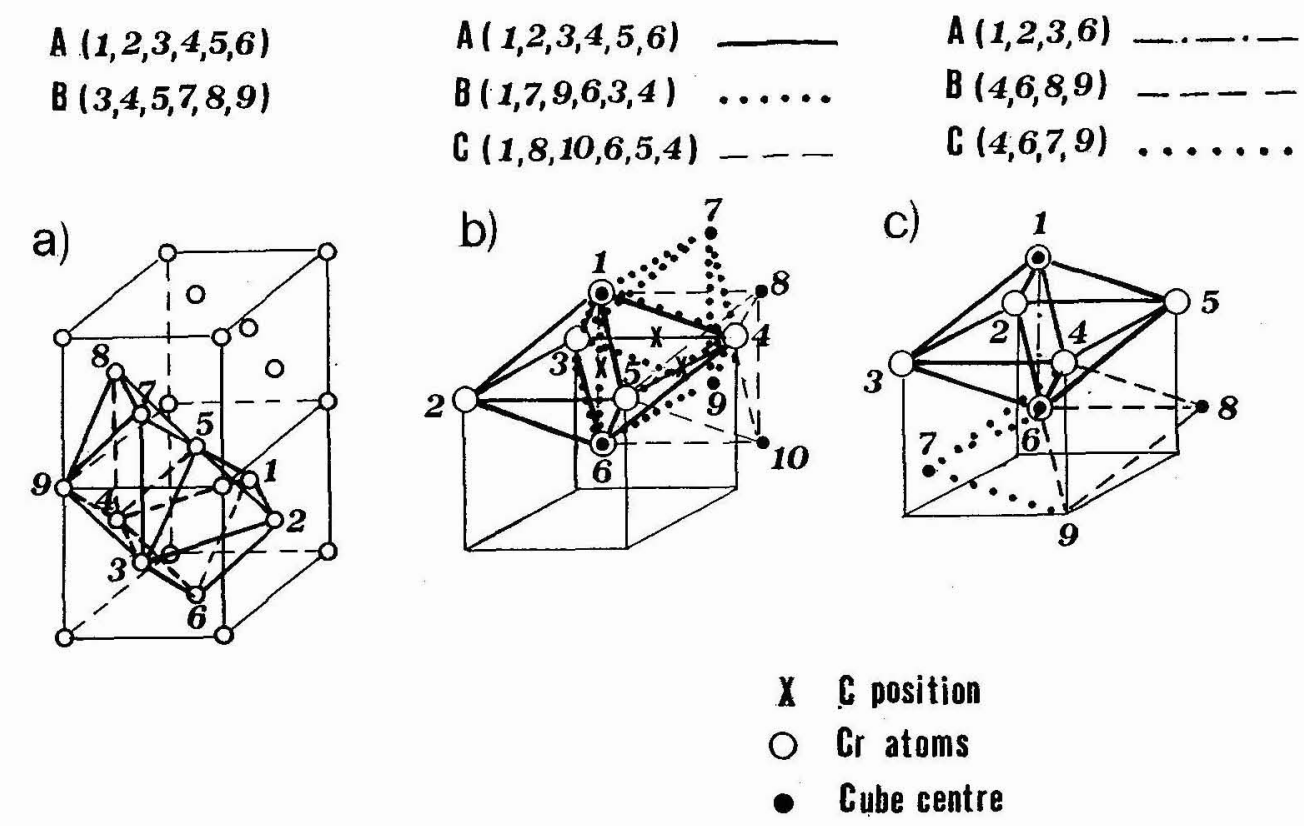

Figure 2: In 2-a difference between octahedra A and B with common face in fcc lattice of $\gamma$-Fe. In 2-b octahedron A in bcc lattice with all corners occupied by $\mathrm{Cr}$ and $\mathrm{B}, \mathrm{C}$ interlaced octahedra with common face and both with $4 \mathrm{Cr}$ atoms. In 3-c octahedron in bcc with all corners occupied by $\mathrm{Cr}$ and with inner $\mathrm{A}$ tetrahedron with possible jumps to tetrahedra all with $4 \mathrm{Cr}$ atoms; $\mathrm{B}$ and $\mathrm{C}$ neighbour tetrahedra with common face and both with $2 \mathrm{Cr}$ atoms. $\mathrm{C}, \mathrm{Cr}$ and cube center atoms in $2-\mathrm{b}-\mathrm{c}$ as in evidence at the bottom.

In the fcc structure of austenite neighbour octahedral cells with common face are not equal (fig.2-a),one with one octahedral interstice $(d=0.103 \mathrm{~nm})$, the other with tetrahedral interstices $(d=0.056 \mathrm{~nm})$ : this explains the absence of the $\mathrm{C}_{-} \mathrm{Cr}_{6}$ peak with the samples fast quenched from the austenitization temperature, since it would require couples of equivalent octahedra with common face and with $6 \mathrm{Cr}$ atoms at the corners. 


\begin{abstract}
Always referring to treatment $\mathrm{A}$ the $\mathrm{C}-\mathrm{Cr}_{4}$ peak accompanying the $\mathrm{C}-\mathrm{Cr}_{6}$ one may find an explanation by considering interlaced octahedra obtained by displacements of $1 / 2$ of the cube side; as shown in fig.2-b a base octahedron with $6 \mathrm{Cr}$ atoms (A) appears thus connected with octahedra labelled $\mathrm{B}$ and $\mathrm{C}$ with only 4 corners occupied by $\mathrm{Cr}$ and with common face, thus explaining the $\mathrm{C}-\mathrm{Cr}_{4}$ peak.

Jumps between equivalent tetrahedral sites in the interior of single octahedra with all corners occupied by $\mathrm{Cr}$ appear instead of better consistency with peaks $\mathrm{C}-\mathrm{Cr}_{4}$ and $\mathrm{C}-\mathrm{Cr}_{2}$ coming about after treatment $\mathrm{B}$. As shown in fig.2-c, in the case of tetrahedral jumps there are in fact two sets of couples for jumping, with 4 and with $2 \mathrm{Cr}$ atoms into and at the boundary of the octahedron with the corners occupied by $\mathrm{Cr}$.

As shown by fig.2-b, the peak $\mathrm{C}$ - $\mathrm{Cr}_{4}$ might be also due to jumps between the octahedra interlaced with the basic one; in this case however they occur at the boundaries octahedra with 3 corners occupied by $\mathrm{Cr}$ and with common face, not agreing with the occurrence of only peak $\mathrm{C}-\mathrm{Cr}_{2}$ which is instead consistent with the tetrahedral jumps.

The absence of a $\mathrm{C}-\mathrm{Cr}_{3}$ peak after the $\mathrm{A}$ treatment is on the other hand a negative aspect for the explanation considered with respect to this treatment, since groups of octahedra with all comers occupied by $\mathrm{Cr}$ are accompanied at the boundaries by $\mathrm{C}-\mathrm{Cr}_{3}$ equivalent octahedra; the absence of the related $\mathrm{C}-\mathrm{Cr}_{3}$ peaks might be due the low probability of formation of $\mathrm{C}-\mathrm{Cr}_{3}$ associates, depending on the tetrahedrality of $\mathrm{C}$.

Diffusion of the $\mathrm{Cr}$ atoms to form the associates is assumed on account of the high temperatures and of the binding energy of $\mathrm{Cr}$ to $\mathrm{C}$ [2].

Consistently with the results it may be assumed that the different $\mathrm{C}-\mathrm{Cr}_{\mathbf{n}}$ associates act as embryos for martensite nucleation.
\end{abstract}

\title{
5.Conclusions
}

The $\mathrm{Q}^{-1}$ measurements have put into evidence the occurrence, in martensitic steels, of $\mathrm{C}-\mathrm{Cr}_{\mathrm{n}}$ associates with different characteristics depending on high $\mathrm{T}$ treatments leading, before fast cooling to room $\mathrm{T}$, to absence or presence of groups of bcc cells with the fcc ones.

The different martensite properties resulting after the high $\mathrm{T}$ treatments appear thus referable to the $\mathrm{C}-\mathrm{Cr}_{\mathrm{n}}$ associates, higher or lower stability of martensite depending on $\mathrm{C}-\mathrm{Cr}_{4}$ tetrahedral and on $\mathrm{C}-\mathrm{Cr}_{6}$ octahedral associates respectively.

\section{Acknowledgments}

The authors are grateful to Mr. P.Plini for the assistance.

\section{References}

[1] Tomilin I. A., Sarrak V.I., Gorokhova N.A., Suvorova S.O., Zhukov L.L., Phys.Metals Metallogr. 56 (1983) 74-79

[2] Gondi P., Montanari R., Phys. Stat. Sol. (a) 131 (1992) 465-480

[3] Golovin I.S., Sarrak V.I., Suvorova S.O., Dimitryev V.E., Phys. Metals Metallogr., 64 (1987) 115-123

[4] Gondi P., Montanari R., Sili A., Z. Metallkd., 85 (1994) 664-669

[5] Albertini G., Ceretti M., Coppola R., Fiori F, Gondi P., Montanari R., Physica B, 213 \& 214 (1995) 812 -

814

[6] Gondi P., Montanari R., Tata M.E., J.Nucl.Mater.- in print 